OPEN ACCESS

Edited by:

Mina Mazzeo,

University of Salerno, Italy

Reviewed by:

Zhanyong Wang,

Shenyang Agricultural University,

China

Pawet Chmielarz,

Rzeszów University of Technology,

Poland

*Correspondence:

Nadia Lotti

nadia.lotti@unibo.it

Alessandro Pellis

alessandro.pellis@boku.ac.at

Specialty section:

This article was submitted to

Polymer Chemistry,

a section of the journal

Frontiers in Chemistry

Received: 06 September 2021 Accepted: 29 September 2021 Published: 15 November 2021

Citation:

Bertolini FA, Soccio M, Weinberger S, Guidotti G, Gazzano M, Guebitz GM, Lotti N and Pellis A (2021) Unveiling the

Enzymatic Degradation Process of

Biobased Thiophene Polyesters.

Front. Chem. 9:771612.

doi: 10.3389/fchem.2021.771612

\section{Unveiling the Enzymatic Degradation Process of Biobased Thiophene Polyesters}

\author{
Federico A. Bertolini ${ }^{1}$, Michelina Soccio ${ }^{2}$, Simone Weinberger ${ }^{1}$, Giulia Guidotti ${ }^{2}$, \\ Massimo Gazzano ${ }^{3}$, Georg M. Guebitz ${ }^{1,4}$, Nadia Lotti ${ }^{2 *}$ and Alessandro Pellis ${ }^{1,4,5 *}$ \\ ${ }^{1}$ Department of Agrobiotechnology, Institute of Environmental Biotechnology, University of Natural Resources and Life Sciences, \\ Vienna, Tulln an der Donau, Austria, ${ }^{2}$ Department of Civil, Chemical, Environmental and Materials Engineering, University of \\ Bologna, Bologna, Italy, ${ }^{3}$ Organic Synthesis and Photoreactivity Institute, CNR, Bologna, Italy, ${ }^{4}$ Austrian Centre of Industrial \\ Biotechnology, Tulln an der Donau, Austria, ${ }^{5}$ Core Facility Bioactive Molecules Screening and Analysis, University of Natural \\ Resources and Life Sciences, Vienna, Tulln an der Donau, Austria
}

In the past 20 years, scientific research focused on the identification of valid alternatives to materials of fossil origin, in particular, related to biobased polymers. Recently, the efforts led to the synthesis of thiophene-based polymers (TBPs), a new class of polyesters based on 2,5-thiophenedicarboxylic acid (TPCA) that can be industrially produced using biomass-derived molecules. In this study, TBPs were synthesized using diols with different chain length (from C4 to C6) leading to poly(butylene 2,5thiophenedicarboxylate) (PBTF), poly(pentamethylene 2,5-thiophenedicarboxylate) (PPeTF), and poly(hexamethylene 2,5-thiophenedicarboxylate) (PHTF), respectively, that were processed to thin films. To investigate enzymatic hydrolysis of these polymer films, cutinase 1 (Thc_cut1) and cutinase 2 (Thc_cut2) from Thermobifida cellulosilytica were recombinantly expressed in the host $E$. coli and purified. After $72 \mathrm{~h}$ of incubation at $65^{\circ} \mathrm{C}$ with $5 \mu \mathrm{M}$ Thc_cut1, weight loss and HPLC analysis indicated 9, 100, and 80\% degradation of PBTF, PPeTF, and PHTG with a concomitant release of $0.12,2.70$, and $0.67 \mathrm{mM}$ of TPCA. The SEM analysis showed that tiny holes were formed on the surface of the films and after $72 \mathrm{~h}$ PPeTF was completely degraded. The LC-TOF/MS analysis indicated that Thc_cut2 in particular released various oligomers from the polymer during the reaction. In addition, the FTIR analysis showed the formation of novel acid and hydroxyl groups on the polymer surfaces. The results showed that the two used thermostable cutinases are promising biocatalysts for the environmentally friendly degradation of TPCA-based polyesters, in view of a possible sustainable recycling of plastic waste through resynthesis processes.

Keywords: polyesters, thiophene-based polymers, cutinases, circular economy, biodegradability, circular materials

\section{INTRODUCTION}

Global plastics production is continuously increasing, and in 2018, it reached 359 million metric tons, of which 61.8 million metric tons are produced in Europe alone. The public's awareness of the problems caused by pollution due to plastics dispersed in the environment has been increasingly growing in recent years. In the ocean, the presence of the great pacific garbage patch is well known (Lebreton et al., 2018), while recently, evidence has emerged that debris are also accumulating in the 
deep layers of water (Egger et al., 2020). A problem related to human nutrition also emerged as the presence of plastics was found in the fish caught in the North Sea, a region with high fish stocks (Foekema et al., 2013). The current situation and the need for implementing a plastic's circular economy are pushing the development of eco-friendly plastics that are both biobased and biodegradable, being capable of replacing those currently in use. This is especially important for applications where a short product life is expected and contamination prevents recycling such as packaging, consumer products, cosmetics, and healthcare.

The pandemic caused by COVID-19 still afflicting the planet resulted in an increased utilization and disposal of single-use plastics, as proved by the increased demand of plastics by $40 \%$ in packaging and $17 \%$ in other applications, including medical uses. Indeed, safety concerns push consumers to prefer fresh-food packaged in plastic containers to avoid food contamination and to extend the shelf-life.

In this scenario, biodegradable and biobased plastics are the preferred options to efficiently manage eco-friendly plastics waste. On the one side, total biodegradation of waste reduces its volume and the consequent environmental impact; on the other side, a controlled enzymatic biodegradation with the production of the monomer used to produce the starting plastics could represent a valid and more sustainable and specific alternative to chemical recycling, especially for blended materials and mixed wastes.

In the packaging field, the most commonly used plastics are polyolefines (polyethylene and polypropylene) and poly(ethylene terephthalate) (PET), the latter to produce water and soft drink bottles. New routes have been developed for the production of biobased terephthalic acid (TA) (Pellis et al., 2016), but nowadays PET is still almost entirely produced from fossil sources. Research efforts are therefore focusing on replacing TA with compounds obtained from renewable sources. An important step forward in this direction has been made, thanks to the identification of 2,5furandicarboxylic acid (FDCA) as a potential substitute for TA (de Jong et al., 2012), since large-scale production from renewable sources was recently demonstrated (Kim et al., 2018). Starting from PET and replacing TA with FDCA, poly(ethylene 2,5furanoate) (PEF) was produced, as well as other polymers containing FDCA and diols with varying carbon chain length (from 2 to 12 carbon atoms) (Papageorgiou et al., 2016; Arnaud et al., 2017; Guidotti et al., 2020).

Therefore, FDCA-based polymers, such as PEF, have a biobased origin and show excellent results in terms of gas permeability (Burgess et al., 2015), in particular $\mathrm{O}_{2}$-barrier properties (Burgess et al., 2014) and mechanical characteristics (Guidotti et al., 2020). In addition to these features, recent studies have shown that FDCA-based polymers have also a better enzymatic degradability than the TA-based ones (Gamerith et al., 2017; Guidotti et al., 2020).

Recently, a new class of polymers has been synthesized in which the FDCA is replaced by the biobased 2,5thiophenedicarboxylic acid (TPCA) (Weinberger et al., 2017; Guidotti et al., 2018d), in order to obtain high performance polymers. It has been observed that the gas-barrier properties of TPCA-based polymers can be comparable or even better than those of FDCA-based polymers (Weinberger et al., 2017; Guidotti et al., 2018b; Guidotti et al., 2018c; Guidotti et al., 2018d). Among the TPCA-based polymers, the most interesting one is poly(butylene 2,5-thiophenedicarboxylate) (PBTF) since it shows excellent gas-barrier properties and similar enzymatic degradability when compared to poly(butylene furanoate) (Weinberger et al., 2017; Guidotti et al., 2018a).

However, the impact of the diol chain length of TPCA-based polymers on enzymatic hydrolysis has not yet been investigated. Therefore, in this work, two hydrolytic enzymes from Thermobifida cellulosilytica, namely, cutinase 1 (Thc_cut1) and cutinase 2 (Thc_cut2), were used to investigate the hydrolysis of poly(pentanediol 2,5-thiophenedicarboxylate) (PPeTF) and poly(hexanediol 2,5-thiophenedicarboxylate) (PHTF) compared to PBTF.

\section{MATERIALS AND METHODS}

\subsection{Polymer Synthesis}

Prior to high molecular weight polymers' synthesis, esterification of 2,5-thiophenedicarboxylic acid was carried out, according to the procedure already described (Guidotti et al., 2018b). In addition, the diacid and a large excess of anhydrous methanol (1:30 mol) were heated to $70^{\circ} \mathrm{C}$ under nitrogen flux until complete dissolution of the diacid. After that, the mixture was cooled to room temperature, and thionyl chloride, in the same molar amount as the diacid, was added by means of a drip funnel. Then, the solution was reheated to $70^{\circ} \mathrm{C}$ and kept $3 \mathrm{~h}$ under stirring in inert atmosphere before being quenched in an ice-cold water bath. The so-obtained dimethyl2,5-thiophenedicarboxylate, in the form of white powder, was repeatedly washed with cold methanol and dried under vacuum before use.

High molecular weight thiophene-based polyesters such as PBTF, PPeTF, and PHTF were synthesized through twostep melt polycondensation, by treating dimethyl-2,5thiophenedicarboxylate with different diols (in molar amount 1 : 3 with respect to the dimethyl ester) in the presence of titanium tetrabutoxide and titanium isoporopoxide catalysts (200 ppm each). Furthermore, all the reagents were charged in a $500-\mathrm{ml}$ glass reactor, which was put in a silicon oil bath heated to $180^{\circ} \mathrm{C}$. The reaction mixture was kept under nitrogen atmosphere and stirred at $100 \mathrm{rpm}$. When more than $90 \%$ of theoretical methanol was distilled off (about $2 \mathrm{~h}$ after diester dissolution), pressure was gradually reduced to $0.1 \mathrm{mbar}$, while the temperature was increased to $200^{\circ} \mathrm{C}$. At the end of this second phase, which lasted two additional hours after maximum vacuum was applied, the temperature was set to $220^{\circ} \mathrm{C}$ for $15 \mathrm{~min}$, afterward the reaction was stopped and the polymers were discharged.

The as-synthesized polymers were dissolved in chloroform and then purified by precipitation in cold methanol. The purified homopolymers were dried at room temperature for $48 \mathrm{~h}$ before further characterization and processing. Thin films (150 $\mu \mathrm{m}$ thick) were obtained by compression molding using a laboratory press (Carver), by melting the purified polymers between two Teflon sheets and applying a pressure of 5 tons $/ \mathrm{m}^{2}$. The films were then ballistically cooled to room temperature in press. 


\subsection{Molecular, Thermal, and Structural Characterization}

The chemical structure of polymers was checked by ${ }^{1} \mathrm{H}-\mathrm{NMR}$ spectroscopy at room temperature using a Varian Inova 400$\mathrm{MHz}$. Each sample was solved in deuterated chloroform with a concentration of $10 \mathrm{mg} / \mathrm{ml}$.

TGA was carried out under inert atmosphere $\left(\mathrm{N}_{2}\right.$ flow $30 \mathrm{ml} /$ min) through a PerkinElmer TGA7, by heating about $5 \mathrm{mg}$ of polymers at a rate of $10^{\circ} \mathrm{C} / \mathrm{min}$, in the temperature range between 40 and $800^{\circ} \mathrm{C}$.

A PerkinElmer DSC6 was used for the calorimetric measurements. Samples weighing $\sim 8 \mathrm{mg}$ were heated at a rate of $20^{\circ} \mathrm{C} / \mathrm{min}$ from $-40^{\circ} \mathrm{C}$ to a temperature $40^{\circ} \mathrm{C}$ above the melting one (first scan), held for $3 \mathrm{~min}$, then rapidly cooled $\left(100^{\circ} \mathrm{C} / \mathrm{min}\right)$ to $-40^{\circ} \mathrm{C}$ and held there for other $10 \mathrm{~min}$. Finally, they were subjected to the same heating rump as the first scan (second scan).

As to X-ray diffraction (XRD) patterns, scans of films were collected in Bragg-Brentano geometry by means of a Malvern Panalytical MRD system equipped with a copper source $(\mathrm{l}=0.15418 \mathrm{~nm})$. For each step of $0.1^{\circ} 2$-theta was investigated for $25 \mathrm{~s}$ with a multi-channel solid state detector in the range $5.0^{\circ}-60^{\circ}$.

\subsection{Structure of Expression Vectors, Transformation, and Expression of Cutinases From Thermobifida cellulosilytica in Escherichia coli}

The genes encoding Thc_cut 1 and Thc_cut 2 were cloned into the commercial expression vector pET-26b and hence fused at their 3 ' with a sequence encoding for a $6 \mathrm{xHis}-\mathrm{Tag}$. The gene construct is preceded by the T7 promoter and is recognized by T7 RNA polymerase, whose gene is present in engineered strains of Escherichia coli, such as BL21, and whose synthesis is induced by isopropyl $\beta$-D-1-thiogalactopyranoside (IPTG). The two constructs were named pET-[cut1] and pET-[cut2] and used to transform E. coli BL21-Gold D3.

The preparation of each expression vector $(10 \mu \mathrm{l}$, corresponding to ca. $20 \mathrm{ng}$ ) was added to a suspension of E. coli BL21-Gold D3 $(100 \mu \mathrm{l})$ from a cell culture which had achieved the exponential phase and an optical density at $600 \mathrm{~nm}$ (OD600) of 0.3-0.5. Transformation was performed using the heat shock procedure $\left(45 \mathrm{~s}\right.$ at $\left.42^{\circ} \mathrm{C}\right)$. Then, $900 \mu \mathrm{l}$ of LB medium (10 g/L tryptone, $10 \mathrm{~g} / \mathrm{L} \mathrm{NaCl}$, and $5 \mathrm{~g} / \mathrm{L}$ yeast extract) were added and the cells were grown for $1 \mathrm{~h}$ at $37^{\circ} \mathrm{C}$ under agitation at $300 \mathrm{rpm}$. The whole cell suspension was then plated on two nutrient agar (Merck KGaA, Darmstadt, Germany, EMD Millipore Corporation) plates supplemented with kanamycin $(40 \mu \mathrm{g} / \mathrm{ml})$ as the antibiotic. A $100-\mu \mathrm{L}$ aliquot was directly withdrawn and spread on a plate; the remaining cells were centrifuged at $10,000 \mathrm{rpm}$ for $3 \mathrm{~min}$ and inoculated on the agarized medium after being resuspended in $100 \mu \mathrm{l}$ of supernatant. Plates were incubated at $37^{\circ} \mathrm{C}$ overnight. Single colonies grown on the plate were picked and inoculated in $30 \mathrm{ml}$ LB-kanamycin medium in 100-ml shaking flasks and incubated overnight at $37^{\circ} \mathrm{C}$ and $150 \mathrm{rpm}$ on an orbital shaker to obtain a "preculture." Afterward, 20 OD600 of preculture cells were transferred into $200 \mathrm{ml}$ of LB-kanamycin medium in a 500$\mathrm{ml}$ shaking flask, thus giving rise to an "expression culture." The protein production was induced by adding $10 \mu \mathrm{l}$ of IPTG, when the culture OD600 reached values between 0.6 and 0.8 , and after the culture was cooled down to $20^{\circ} \mathrm{C}$. The induced culture was incubated overnight at $20^{\circ} \mathrm{C}$ and $150 \mathrm{rpm}$. The cells were harvested by centrifugation $\left(3,200 \mathrm{~g}, 4^{\circ} \mathrm{C}, 15 \mathrm{~min}\right)$, and the pellet was stored at $-20^{\circ} \mathrm{C}$ until further use.

\subsection{Enzyme Purification}

The cell pellet was resuspended in binding buffer $(20 \mathrm{mM}$ sodium phosphate buffer $\mathrm{pH} 7.4$ and $10 \mathrm{mM}$ imidazole, $500 \mathrm{mM} \mathrm{NaCl}$ ), in the measure of $5 \mathrm{ml}$ buffer/g pellet and sonicated with fourtimes $45 \mathrm{~s}$ pulses, $60 \%$ amplitude under ice using a cell disruptor (BRANSON Ultrasonics). The cell crude extract was clarified by centrifugation $\left(3,200 \mathrm{~g}, 4^{\circ} \mathrm{C}, 15 \mathrm{~min}\right)$, and the proteins of interest were purified from the soluble fraction. Proteins were purified by affinity chromatography on a ready-to-use $5 \mathrm{ml}$ His-trap-FF column operated with the liquid chromatography system $\ddot{A} K T A d e s i g n^{\mathrm{TM}}$ (GE Healthcare). For this reason, the 6xHis peptide was fused over an Ala-Leu-Glu linker sequence to the C-terminal of the cutinases. The elution buffer was $20 \mathrm{mM}$ sodium phosphate buffer $\mathrm{pH} 7.4,500 \mathrm{mM}$ imidazole, and $500 \mathrm{mM} \mathrm{NaCl}$.

For the characterization and storage of cutinases, the elution buffer was exchanged with $100 \mathrm{mM}$ Tris- $\mathrm{HCl} \mathrm{pH} 7.0$ with the use of PD-10 desalting columns (Amersham Biosciences) using the gravity protocol. In brief, the column was preconditioned with $25 \mathrm{ml} 0.1 \mathrm{M}$ Tris-HCl buffer $\mathrm{pH} 7.0$ before $2.5 \mathrm{ml}$ of protein samples were applied. Proteins were finally eluted in $3.5 \mathrm{ml}$ of $0.1 \mathrm{M}$ Tris- $\mathrm{HCl} \mathrm{pH}$ 7.0.

Afterward, the purified protein solution was concentrated using Vivaspin 20 centrifugal concentrators 10,000 Da cut off $\left(4,000 \mathrm{rpm}\right.$ for $30 \mathrm{~min}$ at $\left.4^{\circ} \mathrm{C}\right)$. Enzyme aliquots were stored at $-20^{\circ} \mathrm{C}$. The protein solution was aliquoted and stored at $-20^{\circ} \mathrm{C}$. Before their use, new assays of proteins and activities were carried out to verify that no denaturation event had occurred.

\subsection{Protein Quantification With} NanoPhotometer ${ }^{\circledR}$ and SDS-PAGE Analysis Protein concentrations were determined using a NanoPhotometer ${ }^{\circledR}$ (Implen GmbH, Germany), based on molecular weight $($ Thc_cut $1=29,441 \mathrm{~g} / \mathrm{mol}$ and Thc_cut $2=$ $29,450 \mathrm{~g} / \mathrm{mol}$ ) and extinction coefficient (Thc_cut1 = 36,900 $1 /$ $\mathrm{cmM}$ and Thc_cut2 $=38,3901 / \mathrm{cmM})$ of the cutinases. SDSPAGE was performed according to the Laemmli method using a precasted gel and loading $7 \mu \mathrm{l} /$ well of each sample, along with $5 \mu \mathrm{l} /$ well of protein marker (peqGOLD Protein Marker IV, VWR International, LLC). Gels were stained with Coomassie Brilliant Blue R-250. All measurements were carried out in triplicates.

\subsection{Esterase Activity Assay}

Spectrophotometric measurements of the activity were performed using para-nitrophenyl butyrate ( $\mathrm{p}-\mathrm{NPB})$ as the 
substrate and followed by the development of paranitrophenolate ion (absorption peak at $405-410 \mathrm{~nm}$ ). The whole procedure consists of separately and sequentially preparing a "substrate solution"-also called "solution A"-and a "reaction solution"-also called "solution B"-to which the enzyme is added just before the reaction starts.

Furthermore, solution A consists of $86 \mu \mathrm{l}$ of pNPB and 1,000 $\mu \mathrm{l}$ of 2-methyl-3-butanol; solution B consists of $40 \mu \mathrm{l}$ of solution A and $1,000 \mu \mathrm{l}$ of $0.1 \mathrm{M}$ sodium phosphate $\mathrm{pH}$. Finally, $20 \mu \mathrm{l}$ of enzyme solution was added to $200 \mu \mathrm{l}$ of solution B to start the reaction. The increase of the absorbance was measured at $405 \mathrm{~nm}$, $30^{\circ} \mathrm{C}$, for $5 \mathrm{~min}$, every $18 \mathrm{~s}$, using 96 well plates (Greiner 96 Flat Bottom Transparent Polystyrene) and a Tecan plate reader (Tecan, Grödig, Austria, Infinite M200 PRO).

\subsection{Enzymatic Hydrolysis of TPCA-Based Polyesters}

The polyesters were processed in the form of films of different thicknesses ranging from 102 to $236 \mu \mathrm{m}$. Pieces of $1 \times 0.5 \mathrm{~cm}$ were obtained from each film. To remove possible impurities from the polymer surface, three washing steps were performed: the polymers were first incubated with Triton X-100 (5g/L), $\mathrm{Na}_{2} \mathrm{CO}_{3}(100 \mathrm{mM})$, and ultrapure water. Each washing step was conducted at room temperature stirring at $50 \mathrm{rpm}$ for $30 \mathrm{~min}$. Then, each sample was dried overnight under a fume cupboard at room temperature. Afterward, the films were incubated horizontally in an orbital shaker with $1 \mathrm{ml}$ of $1 \mathrm{M}$ potassium phosphate buffer $\mathrm{pH} 8$, with $5 \mu \mathrm{M}$ Thc_cut1 or Thc_cut2. Incubations were performed at $50^{\circ} \mathrm{C}$ and $65^{\circ} \mathrm{C}$, under orbital agitation of $150 \mathrm{rpm}$ for 4 days. The samples were withdrawn after $24,48,72$, and $96 \mathrm{~h}$. All reactions were performed in quadruplicate. Blank reactions were performed in the same conditions, without adding the enzyme.

\subsection{Weight Loss Determination}

To evaluate the weight loss of the polymer film, each sample was weighed using a scientific balance with an accuracy of $\pm 0.0001 \mathrm{~g}$ (Sartorius Lab Instruments, MSA225P-1CE-DI, Germany) before and after the hydrolysis reaction. The relative Eppendorf tube in which the reaction was carried out was also weighed for each sample.

$$
\text { Weight loss }(\%)=100-\frac{\text { Polymer final }(m g)}{\text { Polymer initial }(m g)} \times 100 \text {. }
$$

\subsection{High Performance Liquid Chromatography (HPLC-DAD)}

After the enzymatic hydrolysis of the polyester film, the enzyme was removed following the ice-cold methanol precipitation protocol (volumetric ratio 1:1). The samples were centrifuged (Centrifuge $5427 \mathrm{R}$, Eppendorf AG, Hamburg, Germany) at $12,700 \mathrm{rpm}$ at $4^{\circ} \mathrm{C}$ for $15 \mathrm{~min}$. The supernatant was filtered through $0.2 \mu \mathrm{m}$ PTFE filters and filled into HPLC vials. For HPLC (Agilent Technologies, 1260 Infinity, Palo Alto, CA,
United States) measurements, a reversed phase column C18 (Poroshell $120 \mathrm{EC}-\mathrm{C} 18 \quad 2.7 \mu \mathrm{m} \quad 3.0 \times 150 \mathrm{~mm}$ ) was used. Analyses were carried out using methanol $(\mathrm{MeOH}$, phase A) and formic acid $(\mathrm{HCOOH}$, phase B) gradient (see Supplementary Table $\mathbf{S 1}$ for details). The flow rate was set to $0.35 \mathrm{ml} \mathrm{min}^{-1}$ at a constant temperature of $40^{\circ} \mathrm{C}$. The injection volume was $10 \mu \mathrm{l}$. The released products were measured with a photodiode array detector (Agilent Technologies, 1290 Infinity II, Vienna, Austria) at the wavelength of $260 \mathrm{~nm}$. A preparation of 2,5-thiophenedicarboxylic acid was used to obtain different concentrations (from 0.001 to $1 \mathrm{mM}$ ) and loaded as previously described for HPLC samples to obtain a calibration curve and to quantify the eluted dicarboxylic acids. A post time of 4 min was used to equilibrate the column.

\subsection{Fourier Transform Infrared Spectroscopy}

The polymer film surfaces before and after hydrolysis were characterized using a PerkinElmer Spectrum 100 FT-IR Spectrometer. Spectra were collected at a resolution of $4 \mathrm{~cm}^{-1}$ for 32 scans. All spectra were recorded at room temperature over the wavelength interval between 4,000 and $650 \mathrm{~cm}^{-1}$. The normalization was made on the peak at $1703 \mathrm{~cm}^{-1}$ that corresponds to the $\mathrm{C}=\mathrm{O}$ bond of the carbonyl group of the carboxylic acid and it is not changing with the hydrolysis catalyzed by the cutinases. The bands were assigned as follows: $1,236 \mathrm{~cm}^{-1} v(\mathrm{C}-\mathrm{O}-\mathrm{C}), 1,081 \mathrm{~cm}^{-1}$, and $1,030 \mathrm{~cm}^{-1} v$ (C-O). Normalization was based on the peak at $1,073 \mathrm{~cm}^{-1}$ assigned to $v(\mathrm{C}=\mathrm{O})$.

\subsection{Liquid Chromatography-Time-of-Flight/Mass Spectrometry}

Liquid chromatography-time-of-flight/mass spectrometry (LCTOF/MS), in positive ionization mode, was used to qualitatively identify the released soluble oligomers. The analytes were separated using an HPLC (1260 series, Agilent Technologies, Palo Alto, CA) equipped with a reversed-phase C18 rapid resolution column (Zorbax Eclipse XDB, Agilent Technologies) of $50 \mathrm{~mm}$ by $2.1 \mathrm{~mm}$ and $1.8 \mu \mathrm{m}$ particle diameter. Column temperature was $40^{\circ} \mathrm{C}$. Mobile phase A consists of $20 \mathrm{mM}$ ammonium formiate $\mathrm{NH}_{4} \mathrm{COOH}$ in ultrapure $\mathrm{H}_{2} \mathrm{O}$ and mobile phase $\mathrm{B}$ was ultrapure acetonitrile (see Supplementary Table S2 for details).

The flow rate was $0.5 \mathrm{ml} \mathrm{min}{ }^{-1}$ and the injection volume was $20 \mu \mathrm{l}$. This HPLC system was connected to a time-of-flight mass spectrometer (6230 TOF LC/MS, Agilent Technologies) equipped with an electrospray interface under the following operating parameters: capillary $3500 \mathrm{~V}$, nebulizer 40 psig, drying gas $8 \mathrm{~L} \mathrm{~min}^{-1}$, gas temperature $300^{\circ} \mathrm{C}$, fragmentator $125 \mathrm{~V}$, skimmer $65 \mathrm{~V}$, and OCT $1 \mathrm{RF} \mathrm{Vpp} 750 \mathrm{~V}$. The mass axis was calibrated using the mixture provided by the manufacturer over the $\mathrm{m} / \mathrm{z}$ 50-3,200 range. A second orthogonal sprayer with a reference solution was used as a continuous calibration using the following reference masses: 121.050873 and $922.009798 \mathrm{~m} / \mathrm{z}$. 

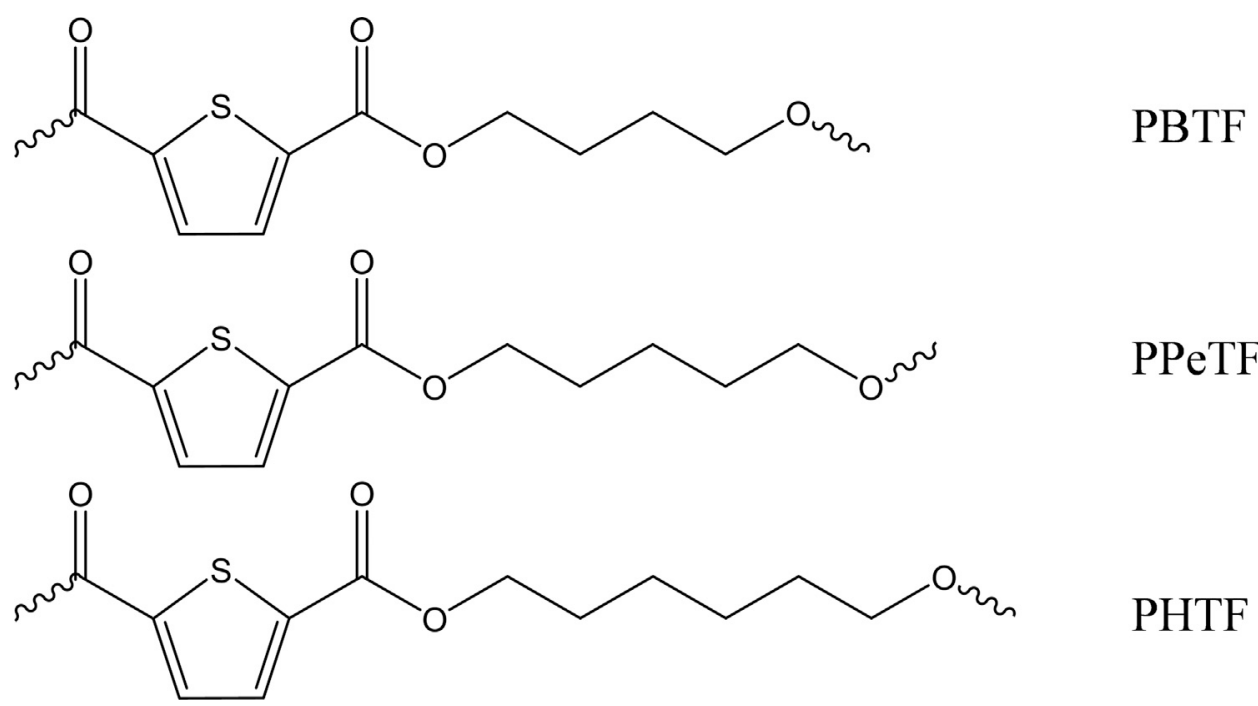

FIGURE 1 | Chemical structure of PBTF, PPeTF, and PHTF.

Spectra were acquired over the $50-3,000 \mathrm{~m} / \mathrm{z}$ range at a scan rate of two spectra per second.

\subsection{Scanning Electron Microscopy}

The morphology of polyester films was qualitatively assessed through scanning electron microscopy (SEM). Control polyester films (without any enzymatic treatment) and enzymatically hydrolyzed films (after 24, 48, 72, and $96 \mathrm{~h}$ ) were surface characterized. All SEM images were acquired by collecting secondary electrons on a Hitachi 3030TM (Metrohm INULA $\mathrm{GmbH}$, Austria) working at EDX acceleration voltage.

\subsection{Gel Permeation Chromatography}

Samples were dissolved in $\mathrm{CHCl} 3$ at a concentration of $2 \mathrm{mg} \mathrm{ml}^{-1}$ and filtered through cotton prior to addition in a HPLC vial. The PBTF samples were instead dissolved in a mixture of $10 \%$ hexafluoro isopropanol in $\mathrm{CHCl}_{3}$. Gel permeation chromatography was carried out at $30^{\circ} \mathrm{C}$ on an Agilent Technologies HPLC System (Agilent Technologies 1260 Infinity) connected to a $17,3696.0 \mathrm{~mm}$ ID $\times 40 \mathrm{~mm}$ L HHR$\mathrm{H}, 5 \mu \mathrm{m}$ Guard column and a 18,055 $7.8 \mathrm{~mm} \mathrm{ID} \times 300 \mathrm{~mm} \mathrm{~L}$ GMHHR-N, $5 \mu \mathrm{m}$ TSKgel liquid chromatography column (Tosoh Bioscience, Tessenderlo, Belgium) using $1 \mathrm{ml} \mathrm{min}^{-1}$ $\mathrm{CHCl}_{3}$ as mobile phase. An Agilent Technologies G1362A refractive index detector was employed for detection. The molecular weights of the polymers were calculated using linear polystyrene calibration standards (Polystyrene standard ReadyCal set Mp 400-2,000,000, Sigma-Aldrich).

\section{RESULTS AND DISCUSSION}

\subsection{Polymer Synthesis and Characterization}

\author{
Poly(butylene 2,5-thiophenedicarboxylate) (PBTF), poly
} (pentamethylene 2,5-thiophene dicarboxylate) (PPeTF), and poly(hexamethylene 2,5-thiophenedicarboxylate) (PHTF) polymers appeared like light brown-colored solids, while after purification they formed white floccules. Their chemical structure (Figure 1) was confirmed by ${ }^{1} \mathrm{H}-\mathrm{NMR}$ analysis (Figure 1). In the case of PBTF, the hydrogen atoms of 1,4-butane moiety $(4 \mathrm{H}, \mathrm{m})$ and $(4 \mathrm{H}, \mathrm{t})$ can be found at $\delta 2.00 \mathrm{ppm}$ and $\delta 4.48 \mathrm{ppm}$, respectively. As to the PPeTF spectrum, the methylene protons of the aliphatic subunit $(2 \mathrm{H}, \mathrm{m}),(4 \mathrm{H}, \mathrm{m})$, and $(4 \mathrm{H}, \mathrm{t})$ were located at $\delta 1.58 \mathrm{ppm}, \delta 1.82 \mathrm{ppm}$ and $\delta 4.34 \mathrm{ppm}$, respectively, while in the case of PHTF spectrum, the hydrogen atoms of glycolic subunit $(4 \mathrm{H}, \mathrm{m}),(4 \mathrm{H}, \mathrm{m})$, and $(4 \mathrm{H}, \mathrm{t})$ can be detected at $\delta$ $1.51 \mathrm{ppm}, \delta 1.81 \mathrm{ppm}$, and $\delta 4.32 \mathrm{ppm}$, respectively. In all cases, the singlet of thiophene ring was located at $\delta 7.70$ (PPeTF and PHTF) or $7.83 \mathrm{ppm}$ (PBTF). No additional peaks were found, proving no impurities were present in the samples.

The polymers were compression molded to form films of thickness around $150 \mu \mathrm{m}$. The results of thermogravimetric analysis (TGA) are reported in Table $\mathbf{1}$ and shown in Figure 2A. It can be observed that all the materials are characterized by high and comparable thermal stability, $\mathrm{T}_{\text {onset }}$ ranging between 376 and $379^{\circ} \mathrm{C}$ and $\mathrm{T}_{\max }$ varying from 400 to $402^{\circ} \mathrm{C}$. In all cases, degradation occurs in two steps, suggesting the same decomposition process. No residual char was present at $800^{\circ} \mathrm{C}$.

First DSC scan profiles are shown in Figure 2B, the corresponding results being listed in Table 1 . As it can be seen, DSC traces show a baseline deviation due to glass-torubber transition followed by endothermic phenomena at higher temperature. In the case of PBTF, the low intensity endothermic phenomenon occurring at lower temperature around $55^{\circ} \mathrm{C}$ (associated heat around $4 \mathrm{~J} / \mathrm{g}$ ), just above glass transition phenomenon, has been previously associated to a mesophase (a 1-D/2-D order phase) arising from $\pi-\pi$ stacking among thiophene rings (Guidotti et al., 2018b; Guidotti et al., 2018c). The most intense endothermic process at higher 
TABLE 1 | Thermal characterization data (TGA and DSC) of the thiophene-based polymers described in this work.

\begin{tabular}{|c|c|c|c|c|c|c|c|c|c|c|c|c|c|c|}
\hline & \multicolumn{2}{|c|}{ TGA } & \multicolumn{6}{|c|}{ First DSC scan } & \multicolumn{6}{|c|}{ Second DSC scan } \\
\hline & $\mathbf{T}_{\text {onset }}{ }^{\circ} \mathbf{C}$ & $\mathbf{T}_{\max }{ }^{\circ} \mathbf{C}$ & $\mathbf{T}_{\mathrm{g}}{ }^{\circ} \mathbf{C}$ & $\Delta \mathbf{C}_{p} \mathbf{J} / \mathbf{g}^{\circ} \mathbf{C}$ & $\mathrm{T}_{1}{ }^{\circ} \mathrm{C}$ & $\mathbf{T}_{2}{ }^{\circ} \mathrm{C}$ & $\Delta \mathrm{H}_{1} \mathrm{~J} / \mathrm{g}$ & $\Delta \mathbf{H}_{2} \mathbf{J} / \mathbf{g}$ & $\mathrm{T}_{\mathrm{g}}{ }^{\circ} \mathrm{C}$ & $\Delta \mathbf{C}_{p} \mathbf{J} / \mathbf{g}^{\circ} \mathbf{C}$ & $\mathbf{T}_{\mathrm{c}}{ }^{\circ} \mathrm{C}$ & $\Delta \mathbf{H}_{\mathrm{c}} \mathbf{J} / \mathbf{g}$ & $\mathbf{T}_{\mathbf{m}}{ }^{\circ} \mathbf{C}$ & $\Delta \mathbf{H}_{\mathrm{m}} \mathbf{J} / \mathbf{g}$ \\
\hline PBTF & 376 & 400 & n.d & n.d & 55 & 147 & 5 & 29 & 25 & 0.237 & 88 & 28 & 147 & 28 \\
\hline PPeTF & 380 & 402 & 8 & 0.123 & 56 & 65 & 24 & 6 & 8 & 0.308 & - & - & - & - \\
\hline PHTF & 379 & 402 & 6 & 0.132 & 51 & 95 & 9 & 25 & 1 & 0.359 & - & - & - & - \\
\hline
\end{tabular}

temperature is instead due to the melting of the crystalline portion of the film (Guidotti et al., 2018b; Guidotti et al., 2018c). The endothermic phenomenon present in the PPeTF DSC trace is broad (the process starts at around $45^{\circ} \mathrm{C}$ ) and asymmetric, suggesting it results from the superimposition of two endothermic phenomena. The most intense and lowest temperature peak could be presumably associated with a meso form coexisting with crystals characterized by a low degree of perfection (melting at $\left.56^{\circ} \mathrm{C}\right)$, the highest temperature $\left(\approx 65^{\circ} \mathrm{C}\right)$ shoulder on the contrary due to the melting of the crystalline portion of the material. The heats associated to the two phenomena are reported in Table 1. Lastly, in the case of PHTF, two well-separated endothermic phenomena are present: one at lower temperature starting at around $40^{\circ} \mathrm{C}$ and centered at $51^{\circ} \mathrm{C}$, again, due to meso phase and poor crystallinity, the other at around $95^{\circ} \mathrm{C}$ ascribable to the melting of crystalline phase.

From the comparison of melting temperature values, the polymer containing an odd number of methylene groups in the glycol subunit presents the lowest Tm; considering the two samples with even number of carbon atoms in the aliphatic segment, it can be noted that the Tm value decreased with glycol subunit length. As far as the expected Tm trend is concerned, polymers containing longer aliphatic chains (glycol subunit) are more flexible, thus crystallizing more readily and melting at higher temperature. The observed trend on the contrary, evidenced an even-odd effect, the polyesters with an even number of carbon atoms per repeat units, i.e., PBTF and PHTF with 4 and 6 per repeat units, respectively, having higher melting points than PPTeF, which is the only one characterized by an odd number of carbon atoms (de Jong et al., 2012).

Therefore, flexibility is not the only parameter that has to be taken into consideration, but also chain symmetry and conformation (Guidotti et al., 2018d).

As for the crystallinity degree, as expected the even $C$ number containing glycol subunit are the most crystalline, PBTF film being slightly more crystalline than PHTF. In the second DSC scan (Table 1), after rapid cooling from the molten state, in all cases the materials turned out to be amorphous, although with some differences. In fact, PBTF behavior is typical of an amorphous material able to crystallize during heating, while for PPeTF and PHTF only baseline deviation due to glass-torubber transition is present. As far as the glass transition value is concerned, it regularly decreased with glycol sub-unit length, as expected, considering the well-known flexibilizing effect imparted to the polymer chain by methylene group segments. From the Tg values measured in the second scan it is evident that at room temperature the amorphous phase of PBTF film is not completely mobile, whereas PPeTF and PHTF films are in the rubbery state. If we consider the enzymatic experiments were carried out at 50 and $65^{\circ} \mathrm{C}$, all the samples investigated are in the rubbery state, thus they can evolve with time. To gain more insight into sample microstructures, film samples have been subjected to X-ray diffraction (XRD). At first sight, the patterns (Figure 3) appeared quite different. PBTF film shows only broad peaks of low intensity overlapped to a bell-shaped intense background. Relative maxima can be seen at $15.1^{\circ}, 17.0^{\circ}$, $22.9^{\circ}$, and $24.7^{\circ}$ and are compatible with crystalline $\alpha$-PBTF (Guidotti et al., 2018c).

PPeTF sample shows broad peaks or shoulders at $7.5^{\circ}, 16.3^{\circ}$, $18.4^{\circ}, 21.3^{\circ}, 22.6^{\circ}$, and $24.3^{\circ} \mathrm{C}$. The PHTF profile is characterized by well defined peaks identified at $6.5^{\circ}, 19.2^{\circ}, 20.0^{\circ}, 22.2^{\circ}, 24.4^{\circ}$, $28.1^{\circ}$, and $31.3 \mathrm{C}^{\circ}$, clearly indicating an elevated crystallinity of the sample. This pattern is comparable with the one reported by other authors (Guidotti et al., 2018c).

\subsection{Enzymes Expression, Purification, and Characterization}

The enzymes Thermobifida cellulosilytica cutinase 1 (Thc_cut1) and 2 (Thc_cut2) were produced as recombinant proteins using E. coli as the host. For both proteins, the expression was maximum after 20-24h from induction (Supplementary Figure S1). The purification of the His-tagged Thc_cut1 and Thc_cut2 was carried out on the soluble fraction via IMAC using a chromatograph and analyzed by SDS-PAGE indicated a $>95 \%$ purity (Supplementary Figure S2). The production and purification yield from $200 \mathrm{ml}$ inflask culture were $26.98 \pm 3.74$ and $33.79 \pm 4.84 \mathrm{mg}$ for Thc_cut1 and Thc_cut2, respectively (Supplementary Figure S3). As a total, $433 \mathrm{mg}$ of purified Thc_cut1 and $653 \mathrm{mg}$ of purified Thc_cut2 were produced.

The activity of Thc_cut1 and Thc_cut 2 was assessed based on the hydrolysis of a small model molecule containing an ester bond, namely, para-nitrophenyl butyrate. The two enzymes showed a comparable activity, with $141.66 \pm 32.18 \mathrm{U} / \mathrm{mg}$ and $159.91 \pm 55.84 \mathrm{U} / \mathrm{mg}$ activity for Thc_cut1 and Thc_cut2, respectively (Supplementary Figure S4).

\subsection{Polyester Hydrolysis}

The 2,5-thiophenedicarboxylic acid-based polymers, PBTF, PPeTF, and PHTF, were subjected to enzymatic hydrolysis by the recombinant Thc_cut1 and Thc_cut2.

Both enzymes were more active on the TPCA-based polymers at $65^{\circ} \mathrm{C}$ than at $50^{\circ} \mathrm{C}$ (Figure 4 and Supplementary Figures S5-S8). This observation is consistent with previously reported data for the hydrolysis of poly(ethylene 2,5-furanoate) (PEF) 


\section{A}

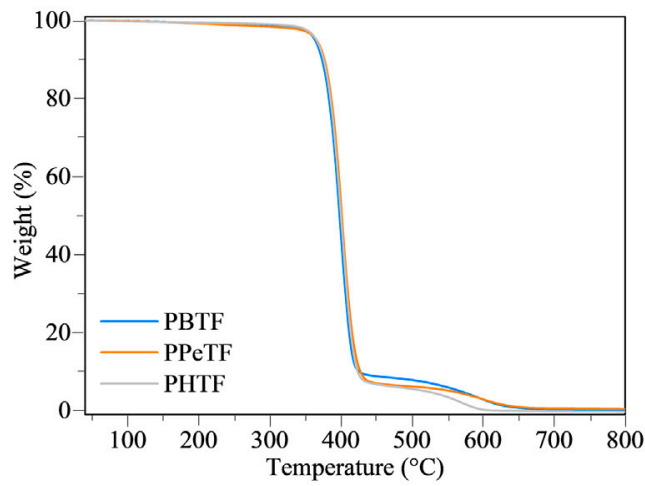

B

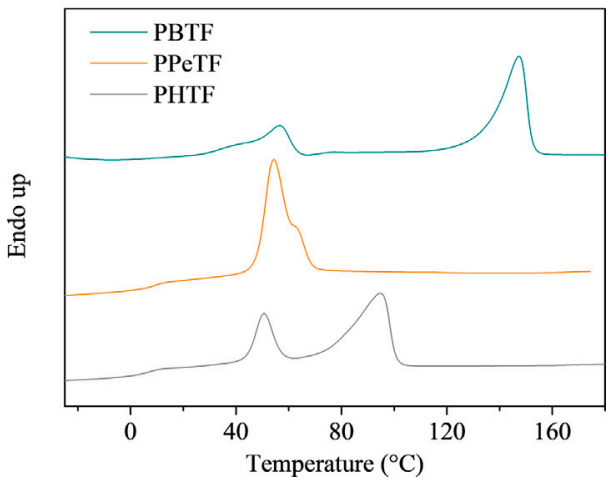

FIGURE 2 | (A) Thermogravimetric curves under nitrogen atmosphere (gas flow $30 \mathrm{ml} / \mathrm{min}$ and heating rate $10^{\circ} \mathrm{C} / \mathrm{min}$ ) and (B) first DSC scan curves of the homopolymers under investigation.

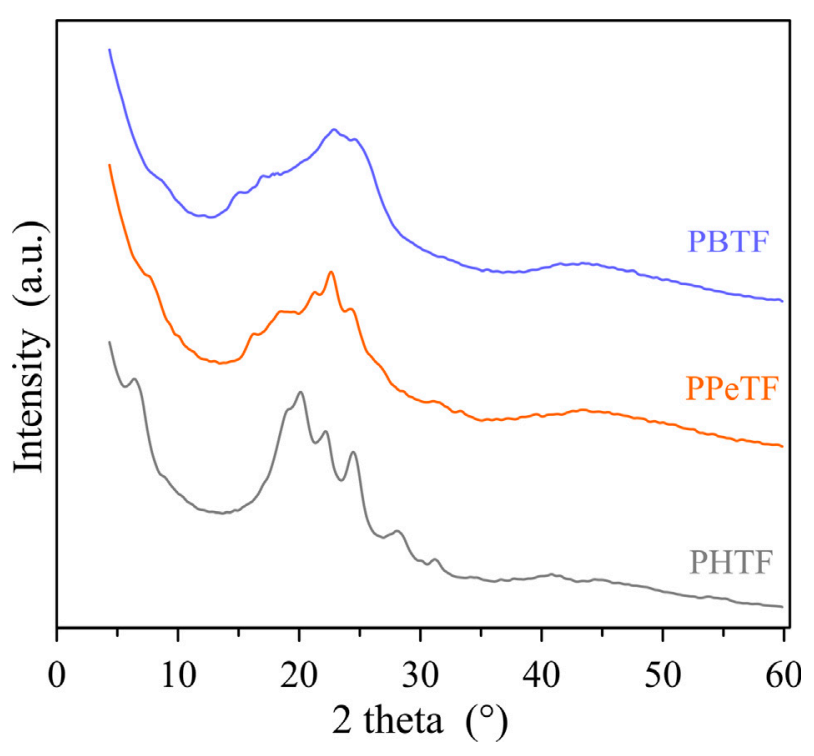

FIGURE 3 | XRD patterns of the investigated polyesters; interlayer distances of the main peaks are indicated in Angstrom.

amorphous films (55\% weight loss in $96 \mathrm{~h}$ ) (Gamerith et al., 2017) and PET. Compared to PET, PPeTF was more efficiently degraded: indeed, we observed a $100 \%$ weight loss with Thc_cut1 and a weight loss $>80 \%$ withThc_cut2 after incubation for $72 \mathrm{~h}$ at $65^{\circ} \mathrm{C}$ (Figures 4A,B, orange bars). Notable results were also obtained with PHTF, polyester containing the 6-carbon diol. In this case, a weight loss of $\sim 80$ and $\sim 50 \%$ after $96 \mathrm{~h}$ at $65^{\circ} \mathrm{C}$ was measured with Thc_cut1 and Thc_cut2, respectively (Figures 4A,B, grey bars). The degradability of PBTF was also assessed, but the measured weight losses (Figures 4A,B, blue bars) were considerably lower (50\%).

The observed trend (PPeTF degrades faster than PHTF, which is degraded faster than PBTF) can be explained considering several factors affecting the kinetics of the degradation process, such as molecular weight, ester group density, hydrophilicity, crystallinity degree, amorphous phase mobility, and melting temperature (Gigli et al., 2019).

Specifically, the higher the ester group density, the shorter the glycol subunit, the hydrophilicity, and the amorphous phase mobility, i.e., the lower the $\mathrm{Tg}$, and the lower the crystallinity degree and the melting temperature, the faster the degradation rate. Comparing the three polyesters under investigation, the ester group density, the hydrophilicity, and the glass transition temperature decrease in the order $\mathrm{PBTF}>\mathrm{PPeTF}>\mathrm{PHTF}$, while the melting temperature follows an even/odd trend with PPeTF sample showing the lowest melting temperature. Lastly, the crystallinity degree changes according to the following trend: $\mathrm{PBTF}>\mathrm{PHTF}>\mathrm{PPeTF}$.

However, it has to be taken into consideration that the degradation experiments have been carried out at higher 

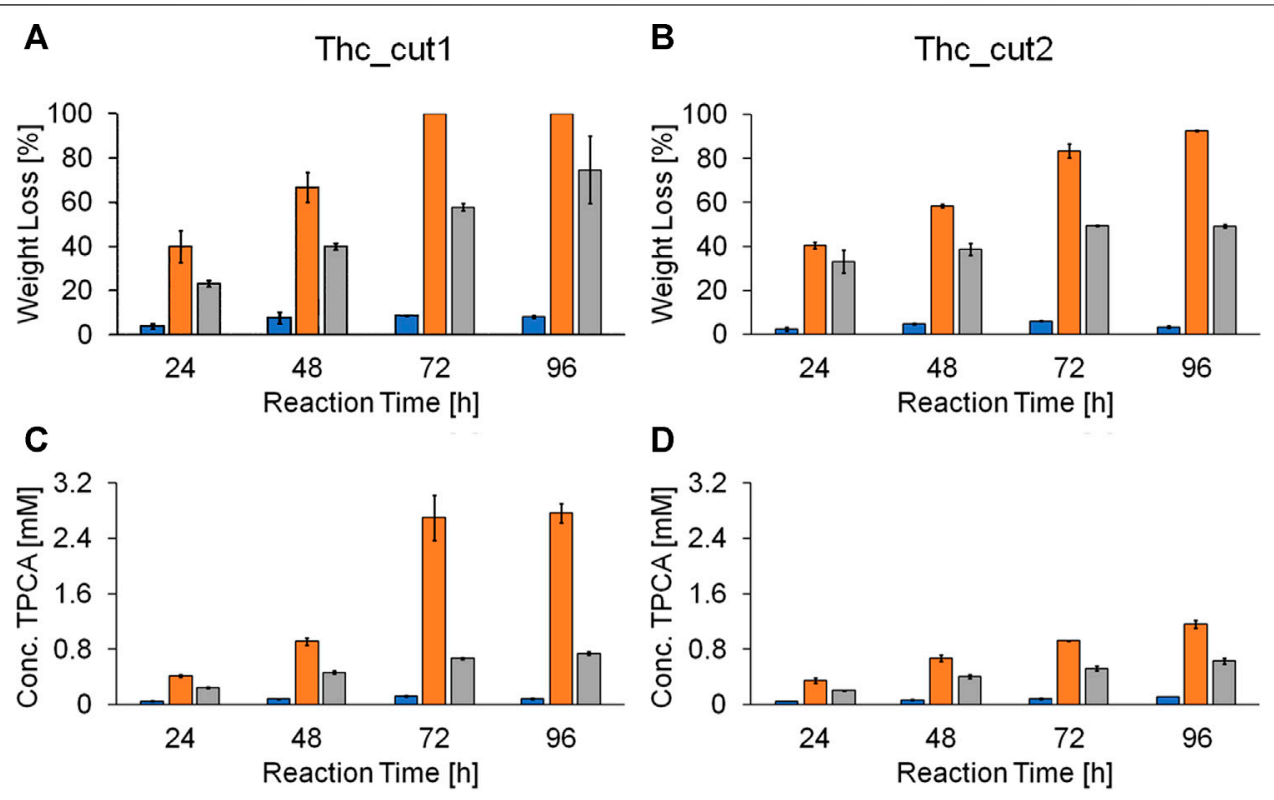

$\square$ PBTF $\square$ PPeTF $\square$ PHTF

FIGURE 4 | Enzymatic hydrolysis of TPCA-based polyesters. Weight loss (panels $\mathbf{A}$ and $\mathbf{B}$ ) and HPLC analysis (panels $\mathbf{C}$ and $\mathbf{D}$ ) of the polyester films treated with Thc_cut1 (panels $\mathbf{A}, \mathbf{C}$ ) and Thc_cut2 (panels $\mathbf{B}$ and $\mathbf{D}$ ) using $1 \mathrm{M} \mathrm{KH}_{2} \mathrm{PO}_{4} / \mathrm{K}_{2} \mathrm{HPO}_{4}$ buffer $\mathrm{pH} 8.0$ at $65^{\circ} \mathrm{C}$. All experiments were performed in quadruplicate and the average values \pm the standard deviations are shown.

temperatures $\left(50\right.$ and $\left.65^{\circ} \mathrm{C}\right)$ than room temperature. At those temperatures, all the investigated samples are characterized by a mobile amorphous phase, the different behaviour in terms of degradability being therefore mainly determined by the crystal phase characteristics. PPeTF resulted to be the fastest degraded polymer (being the least crystalline and having the lowest melting temperature).

The slowest degrading polyester is PBTF mainly because of its high melting crystalline phase, the crystallinity fraction being only slightly higher than that of PHTF.

Furthermore, PBTF was degraded to a significantly lower extent than previously reported for Thc_cutl after $72 \mathrm{~h}$ at $65^{\circ} \mathrm{C}$ (Guidotti et al., 2018a). The difference can be ascribed to the semicrystalline nature of the PBTF film investigated in the present paper. The film previously studied was on the contrary completely amorphous (Guidotti et al., 2018a). As mentioned above, crystallinity makes the enzyme attack more difficult, due to the lower accessibility of polymer chains (Guidotti et al., 2018a).

After the gravimetric determination, gel permeation chromatography of both the neat and degraded film fragments was carried out to detect the size of polymeric chains of PBTF, PPeTF, and PHTF. Overall data indicate that there are no significant differences in chain length between samples of a given polymer before and after the enzymatic treatment (Supplementary Figure S9). These results are in line with recently published data on the hydrolytic degradation of poly(caprolactone) using Candida antarctica lipase (Soccio et al., 2007). The common interpretation is that the hydrolysis of the polymer occurs uniformly on its surface, therefore through a layer-by-layer mechanism, which also confirms the endo-wise activity on the accessible polymer chains previously observed by our group (Guidotti et al., 2018a). The overall effects could be also dependent on the specific polymer chain packing characteristics of each polymer type, which in turn depends on intrinsic/ chemical features of monomers. For example, the higher aromaticity (i.e higher resonance energy) and lower dipole moment of thiophene ring compared to the furan one results in weaker and different polymer chain interactions in PBTF when compared to PBF. In the latter, stronger inter-chain hydrogen bonds are established (Guidotti et al., 2018a; Guidotti et al., 2018c; Wang et al., 2019).

Moreover, when comparing the alkaline and enzymatic hydrolysis of poly(lactic acid), it emerged that the alkali-based hydrolysis of the films led to a strong reduction of the polymer molecular weight (30\% molecular weight decrement after just a 10 min treatment with $\mathrm{NaOH}$ ). On the other hand, the enzymatic hydrolysis with a cutinase from Humicola insolens caused a minimal decrease of molecular weight $(>5 \%$ after a $72 \mathrm{~h}$ treatment) (Bikiaris et al., 2008), which is consistent with our results.

\subsection{Analysis of the Soluble Released Products}

Besides monitoring the weight loss (Figures 4A,B), the film degradability of TPCA-derived polymers was followed analyzing the release of their degradation products (monomers and soluble oligomers) in the solution. Results indicate a higher concentration of released TPCA in samples incubated at $65^{\circ} \mathrm{C}$ rather than at $50^{\circ} \mathrm{C}$ for all polymers, in line with the trend 

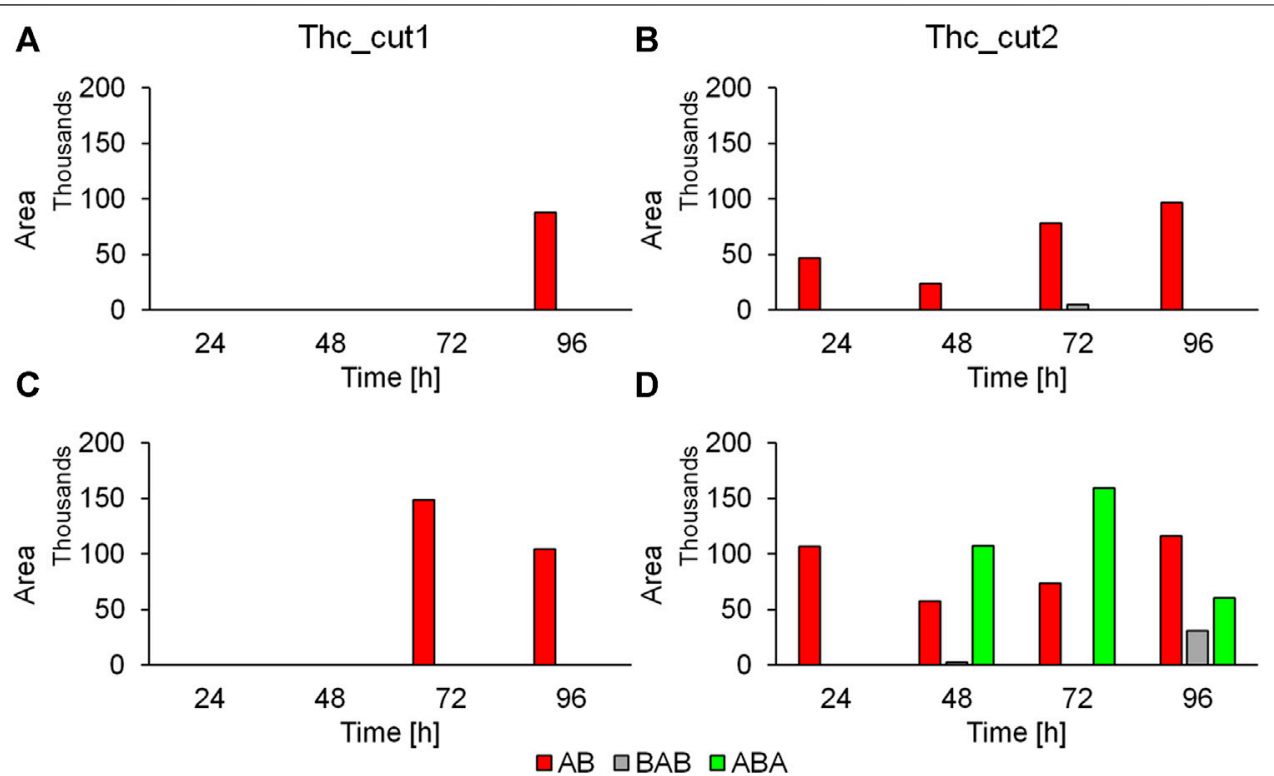

FIGURE 5 | Released oligomers from the PPeTF hydrolysis determined via LC-TOF/MS analysis. Time course reaction showing the released dimers AB, ABA, and BAB for the enzymatic hydrolysis performed at $50^{\circ} \mathrm{C}$ (panels $\mathbf{A}$ and $\mathbf{B}$ ) and $65^{\circ} \mathrm{C}$ (panels $\mathbf{C}$ and $\mathbf{D}$ ) when using Thc_cut1 (panels $\mathbf{A}$ and $\mathbf{C}$ ) and Thc_cut2 (panels $\mathbf{B}$ and $\mathbf{D}$ ). The reactions were performed in $1 \mathrm{M} \mathrm{KH}_{2} \mathrm{PO}_{4} / \mathrm{K}_{2} \mathrm{HPO}_{4}$ buffer $\mathrm{pH}$ 8.0. No released products were detected in the control reactions.

observed for the weight loss analysis. The HPLC results also confirm the highest degradability of PPeTF compared to the other polymers. In fact, the reactions performed at $65^{\circ} \mathrm{C}$ using Thc_cut1 (72 $\mathrm{h}$ reaction time) led to a $2.70 \mathrm{mM}$ concentration of released TPCA for PPeTF, a value that is about 4 times higher compared to the one measured for PHTF $(0.67 \mathrm{mM})$ and even 22 times greater than what was obtained with PBTF $(0.12 \mathrm{mM})$. The higher hydrolytic activity of Thc_cut1 vs Thc_cut2 is confirmed, comparing the concentrations of TPCA released with the two tested enzymes. For example, the hydrolysis of PPeTF performed at $65^{\circ} \mathrm{C}$ and $72 \mathrm{~h}$ led to the release of 2.70 and $0.92 \mathrm{mM}$ of TPCA with Thc_cut1 and Thc_cut2, respectively. As expected, coherently with weight loss measurements, the HPLC results show a lower PBTF degradability compared to PPeTF and PHTF and also respected to the sample previously reported (Guidotti et al., 2018a). Again, this last result can be correlated to the semicrystalline nature of the PBTF film under investigation.

After quantifying the released TPCA, the enzymatic degradation of PPeTF and PHTF was also followed through the release of soluble oligomers using LC-TOF/MS analysis. The types of oligomers found in solution were $A B, A B A$, and $\mathrm{BAB}$, where $\mathrm{A}$ indicates TPCA, and $\mathrm{B}$ the diol (C5 or C6 based on the discussed polymer). When analyzing the results, it must be considered that the oligomers are intermediates, which can be further hydrolyzed and transformed into TPCA monomer, thus increasing -or decreasing-in quantity over time due to the progression of the reaction. Overall, the presence of oligomers together with the release of TPCA confirms the enzyme has both an endo-wise and exo-wise hydrolytic activity.

In general, we can observe that Thc_cut1 produces smaller $(\mathrm{AB})$ and less heterogeneous oligomers $(\mathrm{ABA}$ and $\mathrm{BAB})$ than those generated by Thc_cut2 for both tested polymers (Figure 5).
This can be attributed to the slower hydrolytic reaction of this enzyme. The presence of oligomers from PHTF treated at $50^{\circ} \mathrm{C}$ with Thc_cut2 (Supplementary Figure S10B), and not with Thc_cut1 (Supplementary Figure S10A), is another evidence highlighting the different rate of hydrolysis between the two enzymes. In case the reaction is carried out at higher temperature $\left(65^{\circ} \mathrm{C}\right)$, the oligomers are most likely already hydrolyzed by Thc_cut1, as supported by quantitative HPLC analysis, showing a constant TPCA increase from $0.41 \mathrm{mM}$ (PPeTF) and $0.24 \mathrm{mM}$ (PHTF) after $24 \mathrm{~h}$ to $2.77 \mathrm{mM}$ (PPeTF) and $0.74 \mathrm{mM}$ (PHTF) after $96 \mathrm{~h}$ (Figure 4C).

The LC-TOF/MS data indicate that oligomers are present at higher concentration in the reaction mixtures when hydrolytic degradation is carried out at $65^{\circ} \mathrm{C}$ than at $50^{\circ} \mathrm{C}$, most probably because Thc_cut 1 is more active at $65^{\circ} \mathrm{C}$. For instance, the $\mathrm{AB}$ dimer derived from PPeTF hydrolysis is strongly present (Area = 148870) after a $72 \mathrm{~h}$ reaction at $65^{\circ} \mathrm{C}$ (Figure 5C), but it was not detected at the same time point when the degradation was performed at $50^{\circ} \mathrm{C}$ using Thc_cutl as catalyst (Figure 5A). Some oligomers, in particular the dimer $\mathrm{AB}$, showed a rather fluctuating concentration trend as the reaction proceeds. As aforementioned, this could be due to the subsequent hydrolysis of oligomers into TPCA. This result is evidenced considering the concentration peak of $\mathrm{AB}$ oligomers derived from PPeTF after $72 \mathrm{~h}$ of reaction (Figure 5C): their concentration decreases with time and concomitantly an increase of the TPCA concentration is observed with HPLC (Figure 4C).

\subsection{Polymers Surface Analysis}

The partially hydrolyzed surfaces of the polymers were studied via FT-IR to highlight the effect of enzymatic activity on the polymer film surface. The FT-IR spectra acquired from the C4- and C6- 


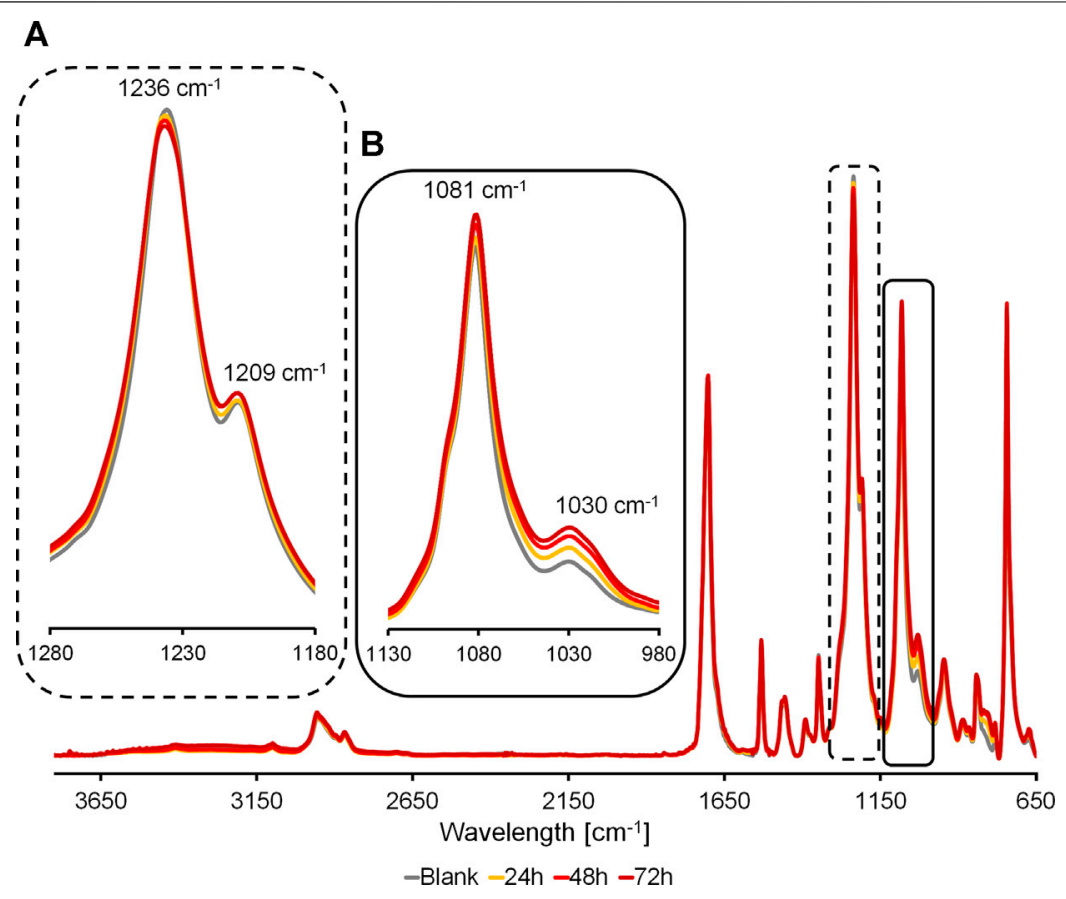

FIGURE 6 | FT-IR spectra of partially hydrolyzed PPeTF films. Samples were treated with Thc_cut 1 at $65^{\circ} \mathrm{C}$ for $48 \mathrm{~h}$. Spectra have been normalized with respect to the intensity of the peak at $1703 \mathrm{~cm}^{-1}$. A: magnification of peaks correlated to the stretching of the $\mathrm{C}-\mathrm{O}$ bond of a primary alcohol and $\mathrm{B}$ : magnification of peaks correlated to the stretching of the ester bond.

polymers treated with cutinases (Supplementary Figures S11, S12) do not show significant differences with respect to the control reactions. This can be due to a marginal impact exerted on these materials by the two enzymes and due to their slow reaction kinetics, as demonstrated by both the weight loss and HPLC results. Instead, the FT-IR analysis of PPeTF, the polymer with the highest degradability according to the weight loss and HPLC analyses, highlights a marked increase of the $1,081 \mathrm{~cm}^{-1}$ and $1,030 \mathrm{~cm}^{-1}$ peaks as the reaction progresses (Figure 6B), while the peak at $1,236 \mathrm{~cm}^{-1}$ decreases (Figure 6A). The peaks at $1,081 \mathrm{~cm}^{-1}$ and $1,030 \mathrm{~cm}^{-1}$ are both correlated to the stretching of the $\mathrm{C}-\mathrm{O}$ bond of a primary alcohol. This $\mathrm{C}-\mathrm{OH}$ group can be formed by breaking of the ester bond and we can observe the corresponding FT-IR peak increases with the progression of the hydrolysis reaction over time. The signal at $1,236 \mathrm{~cm}^{-1}$ associated to the stretching of the ester bond hydrolyzed by the enzyme, decreases with time in agreement with the reduction of the ester bonds content in the material as the hydrolysis reaction proceeds.

SEM analysis of the polymer samples before the treatment and after $48 \mathrm{~h}$ of reaction using the two cutinases showed tiny holes on the film surfaces and confirmed that most effect is obtained for both enzymes at $65^{\circ} \mathrm{C}$ on PPeTF (Figure 7).

In particular, Figure 8 shows the comparison between the effects exerted by Thc_cut 1 and Thc_cut 2 on PPeTF at $65^{\circ} \mathrm{C}$ after $72 \mathrm{~h}$ of reaction. From the images, we can evict both enzymes are active, since both cause the formation of visible holes on the polymer surface; however, with Thc_cut1 being more active than Thc_cut2, fully confirming the trends observed with the other analytic techniques aforementioned.

\subsection{DSC and WAXS Analysis of Partially Degraded Samples}

Supplemenatry Figure S13 and Supplementary Table S3 show the changes in crystallinity of PPeTF and PHTF polyesters before and after the degradation by cutinases at two different temperatures (PBTF was not considered due to its negligible weight loss). In Supplementary Figure S13, first DSC scan curves of partially degraded samples at different timepoints are reported, together with those of the corresponding blanks, while in Supplementary Table S3, melting temperature and the relative $\Delta \mathrm{H}_{\mathrm{m}}$ of partially degraded samples and blanks are listed.

The DSC curves of the partially degraded PPeTF and PHTF at different times during enzymatic degradation at 50 and $65^{\circ} \mathrm{C}$ do not show relevant variations, since the samples and the relative blanks are characterized by the same DSC profile, the slight deviation in $\mathrm{T}_{\mathrm{m}}$ and $\Delta \mathrm{H}_{\mathrm{m}}$ values being within the experimental errors. Anyway, after only $24 \mathrm{~h}$ from the start of enzymatic degradation both the DSC profile of the partially degraded samples and of the corresponding blanks change significantly, respect to that of the compression molded film measured at room temperature. The permanence at 50 or $65^{\circ} \mathrm{C}$ for $24 \mathrm{~h}$ determines the disappearance of the peak at $55^{\circ} \mathrm{C}$ and the intensification of the peak at $65^{\circ} \mathrm{C}$ relative to the melting of crystalline phase, which becomes narrow and symmetrical to indicate a population of crystals with a more uniform degree of perfection. The only difference between the profiles at $50^{\circ} \mathrm{C}$ and those at $65^{\circ} \mathrm{C}$ is the position of melting peak, which is located at higher temperature when the 


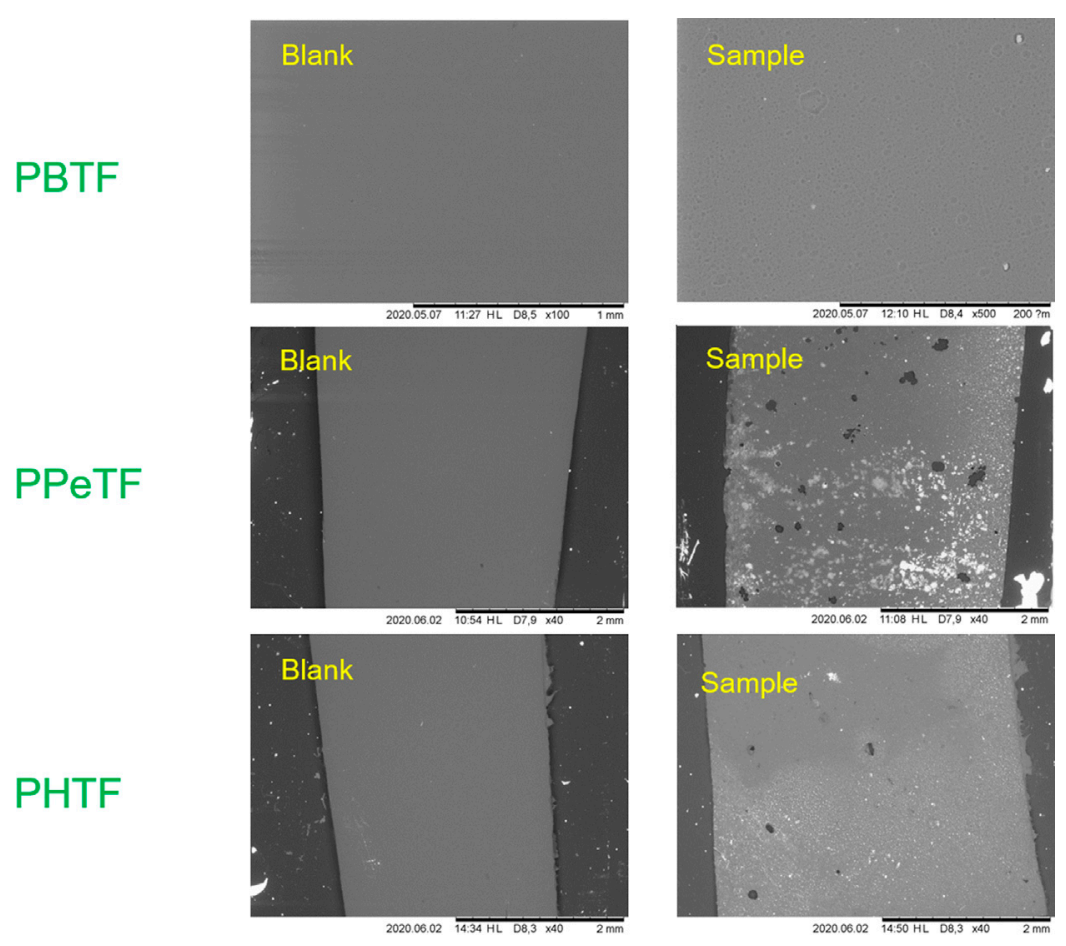

FIGURE 7 | Scanning electron microscopy (SEM) imaging of TPCA-based polyester films after enzymatic hydrolysis. Right side shows the films after enzymatic hydrolysis with Thc_cut1 in $1 \mathrm{M} \mathrm{KPO}$ buffer $\mathrm{pH} 8$ at $65^{\circ} \mathrm{C}$; left side shows the control reactions.
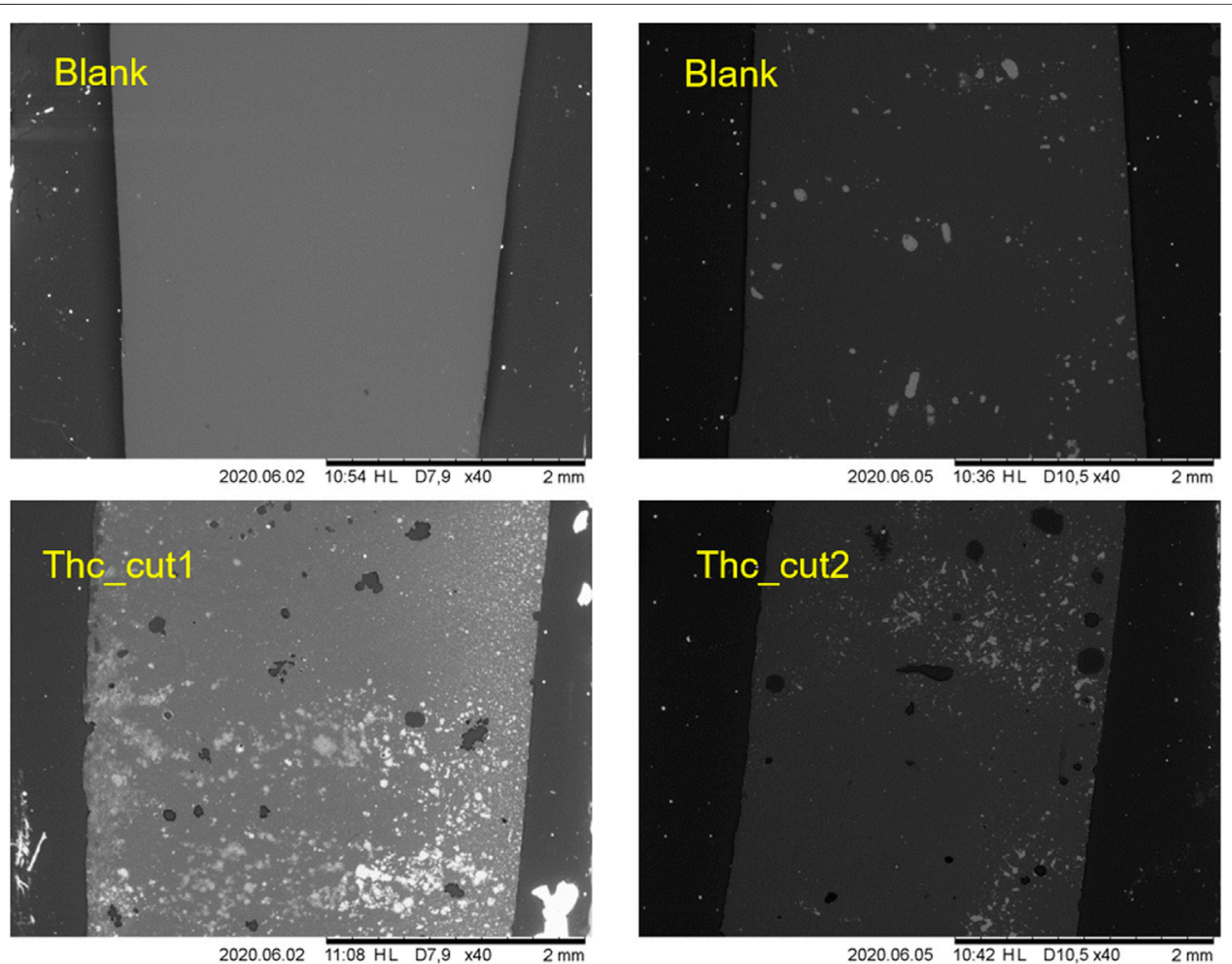

FIGURE 8 | Scanning electron microscopy (SEM) imaging of PPeTF films after enzymatic hydrolysis in $1 \mathrm{M} \mathrm{KPO} \mathrm{buffer} \mathrm{pH} 8.0$ at $65^{\circ} \mathrm{C}$. Left side shows the films hydrolyzed with Thc_cut1; right side shows the films hydrolyzed with Thc_cut2. The upper pictures show the control reactions. Magnification: 40x. 
enzymatic degradation experiments are carried out at $65^{\circ} \mathrm{C}$. As known, both mesophase and poor crystalline phases, if suitably annealed, can evolve into a more perfect, thus higher melting, crystal phase.

In the case of PHTF, the profiles of partially degraded samples together with those of the corresponding blanks are more similar to the profiles of the undegraded compression molded film stored at room temperature. In fact, two endothermic phenomena are still evident, even though they appear to be less separated, due to the shift to higher temperatures of the endo peak at lower temperature.

The intensity ratio between the two endothermic peaks changes at both enzymatic degradation temperatures, the peak at lower temperature becoming even more intense at $65^{\circ} \mathrm{C}$. Again, such results can be explained as due to conversion of the mesophase and less perfect crystals into more perfect 3-D ordered phase.

The increment of sample crystallinity degree regards in equal measure both blanks and enzymatically degraded samples indicating that the result is due to the permanence of films at a temperature above $\mathrm{T}_{\mathrm{g}}$, where amorphous macromolecular chains are mobile and mesophase and poor crystals can evolve to more perfect 3-D crystalline phase.

The XRD patterns collected on samples at different times during the enzymatic degradation at $50^{\circ} \mathrm{C}$ do not present prominent variations as shown in Supplementary Figure S14, in agreement with DSC data. The profiles do not change in shape and peak area, with respect to the bell-shaped halo due to amorphous component. Accordingly, we can state the process does not induce any change in crystal structure and the variations of crystallinity index at the longer times are within the experimental errors. The profile intensities of $96 \mathrm{~h}$ samples are significantly weak compared to the control, confirming a strong sample depletion. Patterns of the samples incubated at $65^{\circ} \mathrm{C}$ show analogous results.

In conclusion, on the basis of the obtained results, two scenarios could be plausible: 1) enzymatic degradation simultaneously occurred at crystalline and non-crystalline regions and 2) degradation occurs preferentially at the amorphous regions, but the extensive surface degradation of amorphous phase determined the detachment of the crystalline phase of the outermost layer.

\section{CONCLUSION}

This work explores for the first time the enzymatic hydrolysis of 5- and 6-carbon-containing diol subunit polymers such as PPeTF and PHTF, while investigates the semicrystalline PBTF (containing 4-carbon atoms diol), the data previously published regarding on the contrary amorphous PBTF film.

As concerning the degradation of polyester biofilms, Thc_cut1 and Thc_cut2 exhibit better activity at high temperatures $\left(65^{\circ} \mathrm{C}\right.$ vs. $\left.50^{\circ} \mathrm{C}\right)$, with Thc_cutl being more active than Thc_cut2. Both enzymes show an endo-wise activity, which can likely be exerted randomly along the polymer backbone. It is known that the endo-wise activity is not only due to the characteristics of the enzyme but also due to the characteristics of the polymer, including the characteristics of an ordered phase; mainly, packing efficiency, crystallinity degree, and polymer inter-chain interactions. Weak interchain interactions may favor the random cleavage of ester bonds still enclosed into the polymer film, thus not necessarily implying exo-wise activity to degrade a polymeric matrix. Probably due to the synergistic combination of these properties, related to the enzyme and to the material, it was possible to achieve the complete, or almost complete, polymer degradation within $72 \mathrm{~h}$, as in the case of PPeTF and PHTF. Although the studied polyesters have a very similar chemical structure, the length of the diol chain turns out to impart very different degradability features, with PPeTF and PHTF exhibiting a much faster degradability profile than that of PBTF. Our study draws attention on PPeTF and PHTF and candidates them as excellent biobased and biodegradable materials for replacing oil-based plastics, especially in the field of packaging and thin-film applications.

\section{DATA AVAILABILITY STATEMENT}

The original contributions presented in the study are included in the article/Supplementary Material, and further inquiries can be directed to the corresponding authors.

\section{AUTHOR CONTRIBUTIONS}

FB expressed, purified, and characterized the enzymes. FB and SW carried out the polymer hydrolysis and characterizations of the hydrolyzed samples. FB, NL, and AP wrote the manuscript. GG and MS synthesized the polymers and characterized undegraded and degraded samples. $\mathrm{MG}$ performed the WAXS measurements. GG, MS, MG, and NL analyzed the experimental data. GG, MS, GMG, and MG corrected and reviewed the manuscript. AP and NL designed and supervised the work.

\section{ACKNOWLEDGMENTS}

FB thanks the European Union for financing his Erasmus + traineeship at the University of Natural Resources and Life Sciences of Vienna. The authors thank Sarah Fuerst and Dr. Doris Ribitsch for the help with the enzyme expression.

\section{SUPPLEMENTARY MATERIAL}

The Supplementary Material for this article can be found online at: https://www.frontiersin.org/articles/10.3389/fchem.2021.771612/ full\#supplementary-material 


\section{REFERENCES}

Arnaud, S. P., Wu, L., Wong Chang, M.-A., Comerford, J. W., Farmer, T. J., Schmid, M., et al. (2017). New Bio-Based Monomers: Tuneable Polyester Properties Using Branched Diols from Biomass. Faraday Discuss. 202, 61-77. doi:10.1039/c7fd00057j

Bikiaris, D. N., Papageorgiou, G. Z., Giliopoulos, D. J., and Stergiou, C. A. (2008). Correlation between Chemical and Solid-State Structures and Enzymatic Hydrolysis in Novel Biodegradable Polyesters. The Case of Poly(propylene Alkanedicarboxylate)s. Macromol. Biosci. 8, 728-740. doi:10.1002/mabi.200800035

Burgess, S. K., Karvan, O., Johnson, J. R., Kriegel, R. M., and Koros, W. J. (2014). Oxygen Sorption and Transport in Amorphous Poly(ethylene Furanoate). Polymer 55, 4748-4756. doi:10.1016/j.polymer.2014.07.041

Burgess, S. K., Kriegel, R. M., and Koros, W. J. (2015). Carbon Dioxide Sorption and Transport in Amorphous Poly(ethylene Furanoate). Macromolecules 48, 2184-2193. doi:10.1021/acs.macromol.5b00333

de Jong, E., Dam, M. A., Sipos, L., and Gruter, G.-J. M. (2012). Furandicarboxylic Acid (FDCA), A Versatile Building Block for a Very Interesting Class of Polyesters. Available at: www.avantium.com. doi:10.1021/bk-2012-1105.ch001

Egger, M., Sulu-Gambari, F., and Lebreton, L. (2020). First Evidence of Plastic Fallout from the North Pacific Garbage Patch. Sci. Rep. 10, 7495. doi:10.1038/s41598-020-64465-8

Foekema, E. M., de Gruijter, C., Mergia, M. T., van Franeker, J. A., Murk, A. J., and Koelmans, A. A. (2013). Plastic in North Sea Fish. Environ. Sci. Technol. 47, 8818-8824. doi:10.1021/es400931b

Gamerith, C., Vastano, M., Ghorbanpour, S. M., Zitzenbacher, S., Ribitsch, D., Zumstein, M. T., et al. (2017). Enzymatic Degradation of Aromatic and Aliphatic Polyesters by P. Pastoris Expressed Cutinase 1 from Thermobifida Cellulosilytica. Front. Microbiol. 8, 938. doi:10.3389/fmicb.2017.00938

Gigli, M., Quartinello, F., Soccio, M., Pellis, A., Lotti, N., Guebitz, G. M., et al. (2019). Enzymatic Hydrolysis of Poly(1,4-Butylene 2,5-Thiophenedicarboxylate) (PBTF) and Poly(1,4-Butylene 2,5-Furandicarboxylate) (PBF) Films: A Comparison of Mechanisms. Environ. Int. 130, 104852. doi:10.1016/j.envint.2019.05.046

Guidotti, G., Gigli, M., Soccio, M., Lotti, N., Gazzano, M., Siracusa, V., et al. (2018a). Ordered Structures of Poly(butylene 2,5-Thiophenedicarboxylate) and Their Impact on Material Functional Properties. Eur. Polym. J. 106, 284-290. doi:10.1016/j.eurpolymj.2018.07.027

Guidotti, G., Gigli, M., Soccio, M., Lotti, N., Gazzano, M., Siracusa, V., et al. (2018b). Poly(Butylene 2,5-Thiophenedicarboxylate): An Added Value to the Class of High Gas Barrier Biopolyesters. Polymers 10, 167. doi:10.3390/polym10020167

Guidotti, G., Gigli, M., Soccio, M., Lotti, N., Salatelli, E., Gazzano, M., et al. (2018c). Tailoring Poly(Butylene 2,5-Thiophenedicarboxylate) Features by the Introduction of Adipic Acid Co-Units: Biobased and Biodegradable Aliphatic/Aromatic Polyesters. Polymer 145, 11-20. doi:10.1016/j.polymer.2018.04.063

Guidotti, G., Soccio, M., García-Gutiérrez, M. C., Ezquerra, T., Siracusa, V., Gutiérrez-Fernández, E., et al. (2020). Fully Biobased Superpolymers of 2,5Furandicarboxylic Acid with Different Functional Properties: From Rigid to
Flexible, High Performant Packaging Materials. ACS Sustain. Chem. Eng. 8, 9558-9568. doi:10.1021/acssuschemeng.0c02840

Guidotti, G., Soccio, M., Lotti, N., Gazzano, M., Siracusa, V., and Munari, A. (2018d). Poly(Propylene 2,5-Thiophenedicarboxylate) vs. Poly(Propylene 2,5Furandicarboxylate): Two Examples of High Gas Barrier Bio-Based Polyesters. Polymers 10, 785. doi:10.3390/polym10070785

Kim, M., Su, Y., Fukuoka, A., Hensen, E. J. M., and Nakajima, K. (2018). Aerobic Oxidation of 5-(Hydroxymethyl)Furfural Cyclic Acetal Enables Selective Furan-2,5-Dicarboxylic Acid Formation with $\mathrm{CeO} 2$-Supported Gold Catalyst. Angew. Chem. Int. Ed. 57, 8235-8239. doi:10.1002/anie.201805457

Lebreton, L., Slat, B., Ferrari, F., Sainte-Rose, B., Aitken, J., Marthouse, R., et al. (2018). Evidence that the Great Pacific Garbage Patch Is Rapidly Accumulating Plastic. Sci. Rep. 8, 4666. doi:10.1038/s41598-018-22939-w

Papageorgiou, G. Z., Papageorgiou, D. G., Terzopoulou, Z., and Bikiaris, D. N. (2016). Production of Bio-Based 2,5-Furan Dicarboxylate Polyesters: Recent Progress and Critical Aspects in Their Synthesis and thermal Properties. Eur. Polym. J. 83, 202-229. doi:10.1016/j.eurpolymj.2016.08.004

Pellis, A., Herrero Acero, E., Gardossi, L., Ferrario, V., and Guebitz, G. M. (2016). Renewable Building Blocks for Sustainable Polyesters: New Biotechnological Routes for Greener Plastics. Polym. Int. 65, 861-871. doi:10.1002/pi.5087

Soccio, M., Lotti, N., Finelli, L., Gazzano, M., and Munari, A. (2007). Aliphatic Poly(Propylene Dicarboxylate)s: Effect of Chain Length on Thermal Properties and Crystallization Kinetics. Polymer 48, 3125-3136. doi:10.1016/j.polymer.2007.04.007

Wang, G., Liang, Y., Jiang, M., Zhang, Q., Wang, R., Wang, H., et al. (2019). Synthesis and Characterization of Bio-Based Polyesters from 2,5-Thiophenedicarboxylic Acid. Polym. Degrad. Stab. 168, 108942. doi:10.1016/j.polymdegradstab.2019.108942

Weinberger, S., Canadell, J., Quartinello, F., Yeniad, B., Arias, A., Pellis, A., et al. (2017). Enzymatic Degradation of poly(Ethylene 2,5-Furanoate) Powders and Amorphous Films. Catalysts 7, 318. doi:10.3390/catal7110318

Conflict of Interest: The authors declare that the research was conducted in the absence of any commercial or financial relationships that could be construed as a potential conflict of interest.

Publisher's Note: All claims expressed in this article are solely those of the authors and do not necessarily represent those of their affiliated organizations, or those of the publisher, the editors, and the reviewers. Any product that may be evaluated in this article, or claim that may be made by its manufacturer, is not guaranteed or endorsed by the publisher.

Copyright (c) 2021 Bertolini, Soccio, Weinberger, Guidotti, Gazzano, Guebitz, Lotti and Pellis. This is an open-access article distributed under the terms of the Creative Commons Attribution License (CC BY). The use, distribution or reproduction in other forums is permitted, provided the original author(s) and the copyright owner(s) are credited and that the original publication in this journal is cited, in accordance with accepted academic practice. No use, distribution or reproduction is permitted which does not comply with these terms. 